\title{
Involvement of users and carers in the training of psychiatrists: making it happen
}

\author{
M. Crawford and S. Davies
}

\begin{abstract}
Desplte the widespread bellef that the involvement of users and carers in the training of psychiatrists would provide a valuable addition to the training process, it is clear that many trainees do not recelve this input as part of their current teaching. This article explores some of the questions and concerns that all those parties involved have raised and draws on the experience of users, carers and psychiatrists to address some of these issues and promote the further development of this practice.
\end{abstract}

Following the publication of the Calman Report (Department of Health. 1993) into postgraduate medical training, the ground was set for a new look at the training process within the different sub-specialities of medicine. Because the Royal College of Psychiatrists has an active Patient Liaison Group this debate has, from the start, involved national representatives of a wide range of patient and carer groups. One of several suggestions made by this group was that the training process should include formal contact with those who are on the receiving end of services. This proposal is in line with the recommendations of the Griffiths Report (Department of Health, 1983) that stated the need to draw on the experience and perceptions of patients in order to shape future changes to health care. It comes at a time when concern has been expressed, by both psychiatrists and by users of mental health services, that the style and substance of psychiatric care is discordant with the views and needs of many service users (Rogers et al, 1993; Thomas et al, 1996).

Subsequent discussions in the College have been characterised by the widespread belief that increased contact between service users and psychiatrists in training would be of benefit to both groups, through increased understanding of how practice affects the lives of patients. However, despite this consensus it is also apparent that most trainees do not at this time have such contact. Possible reasons for this shortfall were discussed at a special meeting of the Patients Liaison Group together with rep- resentatives of tutors, trainees and the Dean of the College.

\section{Concerns of users and providers}

A frequently voiced concern of psychiatrists is that views expressed by users involved in training might not be representative of the wider group of users and carers, and that those motivated to take part could present a polarised view of the treatment and services they have received. Concern has also been expressed about whether or not users would have the experience required to make presentations and whether the stress of being involved in teaching sessions could harm a user's mental health. Worries expressed by users mainly concern the role they may be asked to play. Who would determine the content of users' contributions-would users genuinely be able to raise issues that they identify as being important? Finally, both groups have raised a variety of 'structural' problems such as the limited time available for teaching and the competing demands of other subjects taught to psychiatrists in training. The issue of how to reward those involved and the difficulty of making suggestions for involvement on a national basis, when the number and range of groups of users varies dramatically across different parts of the country, were also raised.

\section{Experience of users and providers of services}

While the process of involving users in the training of psychiatrists is at an early stage, users of mental health services have been involved in training social workers for some time (Hastings \& Crepaz-Keay, 1995). This and other aspects of user involvement have been aided by the development of comprehensive information and training materials that users can draw on for advise about issues such as; how to prepare for sessions, how to organise adequate support and the importance of maintaining confidentiality 
(Mental Health Task Force User Group, 1994). In addition to this, the experience of psychiatrists who have been to teaching sessions delivered by users and carers suggests that when these are organised properly they are highly valued by trainees (comments from trainees at the meeting of the Collegiate Trainees Committee of the College, October 1994). In Leicester service users already contribute to the MRCPsych teaching programme and elsewhere users and carers have successfully provided an additional perspective during postgraduate teaching sessions.

\section{Solutions suggested by this experience}

Concerns that users may not be able to play a constructive, balanced and reasoned part in the training of psychiatrists are not supported by experience of user involvement to date. Similarly, while concerns about the nature of the role that users would play have been raised, planning of sessions with discussion of the scope of material to be presented can minimise the potential for misunderstanding. It should be acknowledged that some service users and some service providers may feel that talking about the user perspective is threatening. However, the now routine practice of medical audit suggests that it is possible to be critical of the services clinicians provide in a way which is constructive. Finding practical solutions to the structural problems raised will require flexibility and imagination. Regarding the issue of rewarding users providing training, the circumstances of different users will vary and while for some the limited funds made available locally through sponsorship of meetings will suffice, for others further reward may need to be considered. While in some areas it would not be possible to give adequate coverage to the range of different local groups, in other areas users and carers may not be available to make contributions to the training programme. In such areas teaching might instead take the form of discussions around a reading list of material produced by users and carers.

\section{Conclusions}

Facing the challenge of correcting the current under-representation of a user perspective in the training of psychiatrists will require the active involvement of both parties. Such action should include the following. First, the College should promote the development of links between tutors and academic staff involved in organising training sessions and local groups. Local user and carer groups should be made aware of the commitment that the College has to involving users in training. Members of the Patient Liaison
Group are well placed to assist in publicising this policy through local and regional contacts.

Second, steps should be taken to ensure that user involvement is incorporated into the training process though amendments to College policies on training. These could include the addition of a section to the regulations for entry for the MRCPsych exam stating that a certain number of hours be allocated to training by users and by making user involvement a requirement of approval for training posts-failure to include user involvement in the training process would be noted during accreditation visits and recommendations for change made. Third, the College and user groups should work together to develop other material such as written/video presentations and a reading list that could be used for presenting user perspectives where local groups may not be in a position to provide teaching at this time. Finally, committees within the College that involve tutors, users and trainees will need to both monitor the progress of these changes and, through feeding back further experiences of those who have been involved, inform future changes and development of this policy.

Experience to date suggests that the concerns about the involvement of users and carers in the training of psychiatrists are misplaced and informs the way future involvement can be organised. In the many areas where this process is not already established the initial work involved may be more time consuming than when preparing other sessions, but by providing the opportunity to gain greater understanding of the service we provide, the scope for providing a better service will be enhanced.

\section{References}

DEPARTMENT OF HEALTH (1993) Hospital Doctors: Training for the Future-The Report of the Working Group on Specialist Medical Training. London: HMSO.

- (1983) The Griffiths Report. London: HMSO.

HASTINGS, M. \& CREPAZ-KEAY, D. (1995) The Survivors Guide to Training Approved Social Workers. London: Central Council for Education and Training of Social Work.

MENTAL HEALTH TASK FORCE USER GROUP (1994) Bullding on Experience-A Training Pack for Mental Health Service Users Working as Trainers, Speakers and Workshop Facilitators F54/016 1724IP 5K. London: Department of Health

Rogers, A., PILGRIM, D. \& LACEY, R. (1993) Experiencing Psychiatry-Users' Views of Services. London: Macmillan Press and MIND.

THOMAS, P., Romme, M. \& HAMELunCK. J. (1996) Psychiatry and the politics of the underclass. British Journal of Psychiatry, 169, 401-404.

*M. Crawford, Research Fellow, Section of Epidemiology and General Practice, Institute of Psychiatry, De Crespigny Park, Denmark Hill. London SE5 8AZ; and S. Davies, Senior Registrar, Rehabilitation Services, Towers Hospital, Leicester. 